\title{
BLACK FRIDAY AND CONSUMER MISBEHAVIOR: A QUALITATIVE ANALYSIS OF PAKISTAN'S BLACK FRIDAY SALE
}

\author{
Nainan Nawaz ${ }^{1 *}$, Osman Khan ${ }^{2}$ \\ ${ }^{1}$ PhD Candidate, Department of Business Administration IQRA University, \\ Islamabad, 44000, Pakistan. E-mail: nainannawaz27855@iqraisb.edu.pk \\ ${ }^{2}$ Associate Professor, Department of Business Administration IQRA University, \\ Islamabad, 44000, Pakistan.E-mail: osman.khan@iqraisb.edu.pk
}

*Corresponding Author email: nainannawaz@gmail.com

\begin{abstract}
The purpose of the research was to explore the misbehaviors of Pakistani consumers during the Black Friday sale. The factors that lead the consumers to misbehave in the discounted event were explored as well. This study undertook the consumers who were shopping during the Black Friday sale at the Cetaurus Mega Mall. The observations and images were collected to analyze. The data analysis was done by transcribing major themes. By using these factors a conceptual framework of the consumer misbehavior predictors was proposed. The suggestions to solve these problems were also given to retailers.
\end{abstract}

\author{
Article History \\ Submission: July 28, 2020 \\ Revised: August 21, 2020 \\ Accepted: September 24, 2020 \\ Keywords: \\ Black Friday; \\ Consumer Misbehavior; \\ Pakistan; Retailing
}

Abbreviations: NIL

do

10.31580/jmi.v7i3.1600

\section{INTRODUCTION}

Pakistan is the fastest growing retailing market of the world according to the Euromonitor International research group, due to the growing youth and their easygoing attitude towards the increasing income. Pakistan's retail market is expected to grow by $8.2 \%$ per annum from 2016 to 2021. The middle class of Pakistan is predicted to outshine the middle class of Italy and the U.K. within the estimated period as nearly two-thirds of the population of 207.8 million is under the age of 30 years (Mangi, 2017). Black Friday is one of the most recognized discounts offering events of the year which was started in 1950 after the chaos was created by the companies of the USA after thanksgiving(Pruitt, 2015). The first-ever Black Friday in the 74 years history of Pakistan was hosted by Daraz.pk: An online shopping portal on the 27th of November 2015. This sale broke all the existing records of sale at that time with 1.5 million visiting shoppers and 55\% more purchase orders as compared to any other regular day. The event was a total success in the online retail environment among the youth as well, as the hashtag \#BlackFridayPK trended for 2 consecutive days in Pakistan's top Twitter trends (Tribune 2015). Since the phenomenon of Black

\section{Readers /nsight}


Friday is relatively new for both the Pakistani consumers and retailers (online and offline) it provides a huge gap as well as an opportunity for the researchers to fill and explore. On the 25th of November 2016, the online shopping portal Daraz.pk recorded the first 1 billion rupee sale (for any retailer) in the history of Pakistan during the occasion of the Black Friday sale (Tribune 2016). In a discounted environment with doorbuster offers, consumers have been found to behave badly in multiple locations on different occasions such as Black Friday (Grenoble, 2015).

In a clothing retail shop called Sapphire, women were found fighting for the clothes during the occasion of their 1st-anniversary sale. A video of these Pakistani women fighting over garments went viral in which women were seen pushing, pulling, and throwing the garments as well as each other. This sale by Sapphire was designed like the door-busting sales of Black Friday. The store strike down the limited, widely desired, and heavily marketed products by $50 \%$ of the actual price (Ghazi, 2015). These incidents pose serious consequences for the employees as a result of misbehaving consumers. Consumer misbehavior includes both group and individual actions. It can result in the shape of severe physical, psychological, and/or financial harm to the marketing institutions, their employees, and other consumers (Reynolds \& Harris, 2009). The misbehavior of consumers can have consequences for the fellow consumer as well as on the employee that can affect their job. This type of misbehavior triggers the emotional stressor in the employee so the employee ends up behaving badly with the coworkers and the consumers (Kim \& Qu, 2018). The misbehavior from the consumers' side is a daily routine task for the service employees to be handled, which causes distress, withdrawal, and reduced performance (Yagil, 2017). Recently, a woman at a mall in Lahore Pakistan was seen beating up a salesgirl of a cosmetic shop for not having a mirror. She beat up the employee without any proper reason than not going to get the mirror from another shop herself (Tribune, 2019). Such incidents make it a crucial phenomenon to be explored by the researchers as this posits danger to the employees, fellow consumers, and retailers.

The word consumer misbehavior indicates anticipations about the disrupted behavior that occurs between the consumers, retail workers, and retailers (Lennon, Kim, Lee, \& Johnson, 2017). Consumer misbehavior can be described as the social behaviors of the consumers that negate and disrupt the commonly set standards of consumption in a retail environment. This shows the negative and dark side of the consumers in a retail setting (R.A. Fullerton \& Punj, 2004). The occasion of Black Friday has been an event for frequent consumer misbehavior as the consumers fight over the highly discounted products (Lennon, Lee, Kim, \& Johnson, 2014).

Based on the above-mentioned discussion, the research question and objective of the study are as follows:

RQ: What are the stimulators that trigger the consumers to misbehave during the Black Friday sale event? 
The research objective of the study is as follows:

To explore the stimulating causes that make consumers to misbehave during the Black Friday sale event.

\section{THEORETICAL AND PRACTICAL CONTRIBUTION}

The literature lacks research exploring the stimulators of consumer misbehavior during Black Friday sale in Pakistan's context. The research in consumer behavior literature is restricted to industries such as bars, restaurants, and hotels (Harris \& Reynolds, 2004). This posits a gap in the exploration of other industries as well such as the clothing industry. Moreover, most of the previous studies have been conducted in the United Kingdom and the United States which are developed countries whereas research in the context of developing countries is limited. Especially, when the Black Friday sale event is new to the Pakistani consumers as well. Hoftstede (1991) has described culture as the feelings, thoughts, and actions of individuals. According to him, culture drives the visible and invisible behaviors of humans in a social setting. He has given 6 dimensions of culture that distinguish countries based on their feelings, thoughts, and actions which are power distance, collectivism vs. individualism, uncertainty avoidance, femininity vs. masculinity, short-term vs. longterm orientation, and restraint vs. indulgence (Hofstede, 2011). These developing and developed countries have been recognized to score inversely on these dimensions. For instance, the United Kingdom, the United States, and Pakistan's comparison indicates diverse findings. On the dimension of power distance, Pakistan's estimated score is 55, UK's estimated scores are 35, US's score is 40, for the individualism dimension UK's estimated scores is 89, US's score is 91, and Pakistan's estimated score is 14 (Hofstede-Insights, 2020). There is an evident difference between the American, European, and Asian countries' cultural dimensions making it significant to research the phenomenon. Consumer misbehavior is an unpleasant part of the culture. This type of behavior challenges the foundation of the contemporary consumption societies, the system's capacity to function effortlessly, and implicated norms and expectations (Fullerton \& Punj, 1997). The consumer misbehavior differs on the basis of time, settings, and cultures (Moschis \& Cox, 1989).

No previous studies have garnered data that offers insight into the consumer misbehavior of Pakistan's clothing retail concerning the Black Friday sale. Hence, the current study contributes to the broader retail literature through research and provide insights into the dynamics of consumer misbehavior on Black Friday sale.

\section{LITERATURE REVIEW}

There are some more terms used for such kind of behaviors such as counterproductive behavior, organizational misbehavior, antisocial organizational behavior, organizational deviance, dysfunctional behavior, employee withdrawal, and many more(Everton, Jolton, \& Mastrangelo, 2007) The common types of misbehavior are: 
vandalism, financial frauds involving insurance, payments, credit cards, shoplifting, and physical and verbal excuse (Cova, Gaglio, Weber, \& Chanial, 2018).

\section{CONSUMER MISBEHAVIOR}

The phenomenon of consumer misbehavior (Harris \& Daunt, 2013) has been termed differently by different researchers over time such as jaycustomer behavior (Harris \& Reynolds, 2004), negative consumer behavior (Fullerton \& Punj, 2004), deviance behavior (Reynolds \& Harris, 2006; Raymen \& Smith, 2015; Amine \& Gicquel, 2011; Harris \& Daunt, 2011), and dysfunctional behaviors (Reynolds \& Harris, 2009).

Fullerton and Punj (2004) defined consumer misbehaver as a negative behavior that affects the shopping experience of all the consumers. Such misbehavior can cause physical, psychological, or material loss or all to the fellow consumers, retail employees, or retailers. In such conditions, most of the time the consumers who are not misbehaving get mishandled by others (Ronald A. Fullerton \& Punj, 1993). Consumer misbehavior includes both group and individual actions. It can result in the shape of severe physical, psychological, and/or financial harm to the marketing institutions, their employees, and other consumers (Kim \& Qu, 2018). Wang, Chen, and $\mathrm{Li}$ (2018) found that consumer misbehavior occurs in various organizations and almost all occupations. According to Kim and Qu (2018), the misbehavior of consumers can have consequences for the fellow consumer as well as on the employee that can affect their job. This type of behavior triggers the emotional stressor in the employee so the employee ends up behaving badly with the coworkers and the consumers. Lennon et al. (2014) found that the misbehavior of consumers is a type of non-acceptable behavior socially which drives by self-interest. Consumers tend to behave socially and morally wrong when they perceive the unfair behavior of unpleasant fellow consumers or a huge crowd. They perceive it to be a hazard for their self-interest hence misbehaves. These misconducts and negative behaviors are externally visible and directed. Such actions make the perception of the consumers' conduct in the overall consumption culture in a retail environment ( Fullerton \& Punj, 2004).

Some of the significant studies and the studied variables are as follows: the personality factors, environmental factors, motivational factors, and situational factors (Akbari, Abdolvand, \& Ghaffari, 2016), machiavellianism, consumer alienation, aggressiveness, sensation seeking, and self-esteem(Amelia \& Ronald, 2017), social dimensions and spatio-temporal (Daunt \& Greer, 2015), contextual factors (servicescape and situation-specific variables) and individual factors (personality and demographic variables) (Daunt \& Harris 2012), perceived employee service, deviance consumer repatronage intent, past consumer misbehavior, and severity of consumer misbehavior (Daunt \& Harris, 2014), official classification, perceived risk, norms, intent, perceived outcomes, perceived fairness, past experiences as victim, and moral identity (Dootson, Johnston, Beatson, \& Lings, 2016), personality, attitudes to 
unethical consumer behavior, and shoplifting (Egan \& Taylor, 2010), consumer misbehavior and frontline employees, consumer misbehavior: management strategies and tactics (Harris \& Daunt, 2013), and denial of victim, denial of injury, claim of normalcy, claim of relative acceptability and justification by comparison, appeal to higher loyalties, and denial of responsibility (Harris \& Dumas, 2009). Although many researchers have conducted studies on different variables and contexts in the literature of consumer misbehavior, the research in the context of Black Friday sale is understudy.

\section{BLACK FRIDAY}

Black Friday is one of the most recognized discounts offering events of the year which was started in 1950 after the chaos was created by the people of the USA after Thanksgiving Day before the Christmas holiday (Pruitt, 2015) Many other countries apart from the USA also celebrate this day. The day Black Friday is conventionally known for the outdoor long lines of consumers waiting in the cold weather for the shops to open, chaos, and confusion of consumers after the opening of the retail shops along with the intense crowd, limited number of stock available to be purchased at a low price, and extensive checkout point lines (Simpson, Taylor, O'Rourke, \& Shaw, 2011). Black Friday is not just famous because of the humongous discounted deals the retailers offer but also the chaos, tiffs, tag of war, punching, pulling, and fights created by the consumers in the stores (Grenoble, 2015; Wheatstone et al., 2015).

\section{CONSUMER MISBEHAVIOR AND BLACK FRIDAY}

Lennon, Johnson, and Lee (2011) developed an instrument of consumer misbehavior to identify the relationship of variables after identifying the potential factors of consumer misbehavior. They found that the consumers who perceived that they have planned and put efforts into the Black Friday shopping are the ones expected to misbehave. This factor was also found to be associated with impulsivity. In the Glasgow branch of Tesco, consumers were seen shouting, pushing, pulling, and punching over each other over a reduced-priced TV (Glanfield, Cockroft, \& Smith, 2014). An employee at Wal-Mart Long Island was killed by the wild and rough shoppers who were in a hurry to get through the doors of the store to buy discounted stuff. They did not care about the trampled employee at all, who died eventually. Along with him, four other employees were injured, which included a pregnant woman as well (Blau, 2015). The crowd refused to let others help the injured and said they have been waiting for the store to open since $5 \mathrm{am}$. It was a troop of around 2,000 shoppers (Dubuis \& Bucktin, 2015). This event which occurred in 2008 was a shocker for everyone and required some drastic changes in the security system by the retailers (Blau, 2015). The police of South Wales confirmed receiving multiple calls from the Tesco employees for their safety because of the crowd who showed up for Black Friday sale (Burke \& Agencies, 2014). In the Silverburn area, the Tesco extra was shut down temporarily because of the disarray. And a burning dustbin was also found 
outside the store. In the meantime, the Manchester Police had to go to seven different stores at different locations to control the whole situation caused by the crazy shoppers and the Stretford Tesco extra was also closed down because of the extreme fighting and chaos of the consumers. These Tesco stores were not the only ones that had been closed down but three other Tesco stores also called Scotland Yard to the store for safety reasons because of the crowd's gushes and frays (Glanfield et al., 2014).

Such incidents and behaviors from the consumers make it obligatory for the retailers to control these situations. These incidents make the situation worse for fellow consumers and employees (Moschis \& Cox, 1989). These kinds of incidences decrease the whole consumer experience. As consumer experience is a means of competitive edge these days (Terblanche, 2018). Thus, it is important for the researchers and retailers to know about the factors that trigger and motivates the consumers to misbehave in such a manner.

\section{THEORETICAL PROBLEM}

The purpose of the current research is to explore the stimulating factors that motivate the consumer to misbehave during a Black Friday sale.

\section{METHODOLOGY}

The inductive approach was used for the present study as the study started with exploring and observing the general behaviors of the consumers on Black Friday and then generated the specific factors. The ethnography strategy was used for current research because the research questions were based on the behaviors of Pakistan's consumers during the day of Black Friday. The Pakistani community of consumers was treated as a subcultural group as it is the fast-growing retailing nation of the world (Mangi, 2017).

The ethnography approach studies an entire culture or the subcultural groups (Creswell, 2007) so this study took the shopping community of Pakistan during the day of Black Friday as the unit of analysis. This study undertook the consumers and consumers who were shopping on the day of Black Friday in the Centaurus Mega Mall in Islamabad as it is one of the biggest mega malls in Islamabad, Pakistan. The Centaurus Mega Mall was the first mall to open in Islamabad. It has the most notable national and international clothing brands such as Khaadi, Sana Safinaz, Ego, Nishat Linen, Al- Karam along with many more (GraanaBlog, 2019). Thus, it was chosen to conduct the research there. The random purposive sampling type was used because of the larger group of consumers (Creswell, 2007).

To collect the data the researchers started with the observations of the consumers as to how they were behaving in the discounted environment (Creswell, 2007). In the last step, the researcher bought clothes herself to be a part of the environment and talked to the consumers in the long queues about their experience while observing the overall scenario from the perspective of an insider. These steps to collect data were mentioned 
by Creswell (2007). The process of taking the pictures and videography was done in the phase of observation as well for which the retailers were asked verbally for their permission as they were too busy to sign a consent form. The researcher started as an outsider and ended with being an insider by participating in the whole activity. For the recording of the field notes a journal was used in which all the details were handwritten. The pictures and videos were taken from the mobile phone. The analysis of data was done by doing coding and the interpretation of the images. The data analysis was done by organizing the files, concluded major themes from the collected data after going through the notes and pictures. Firstly, rough transcriptions were done of the original data then the analysis by keeping the understudied phenomenon was done to generate the themes of the predictors (Moore \& Llompart, 2017). The data tome was not much, hence did not require assistance from the sophisticated data tools.

\section{FINDINGS AND DISCUSSION}

The observational field notes, interview answers, and images were collected as data to be analyzed. While going through the whole coding process of the data and interpreting the images some of the factors emerged as to how the Pakistani consumers treated the Black Friday sale. Those themes are as follows:

\section{CROWD}

The first category was based on the crowd and its characteristics. Since the crowd had many different layers a separate theme was created to give a clear version of Pakistani consumers.

Observation note: All most all of the clothing stores were so crowded that there was no place to set foot there.

Observation note: One uncle said to others that "let's go from here it's too much of a haphazardness"

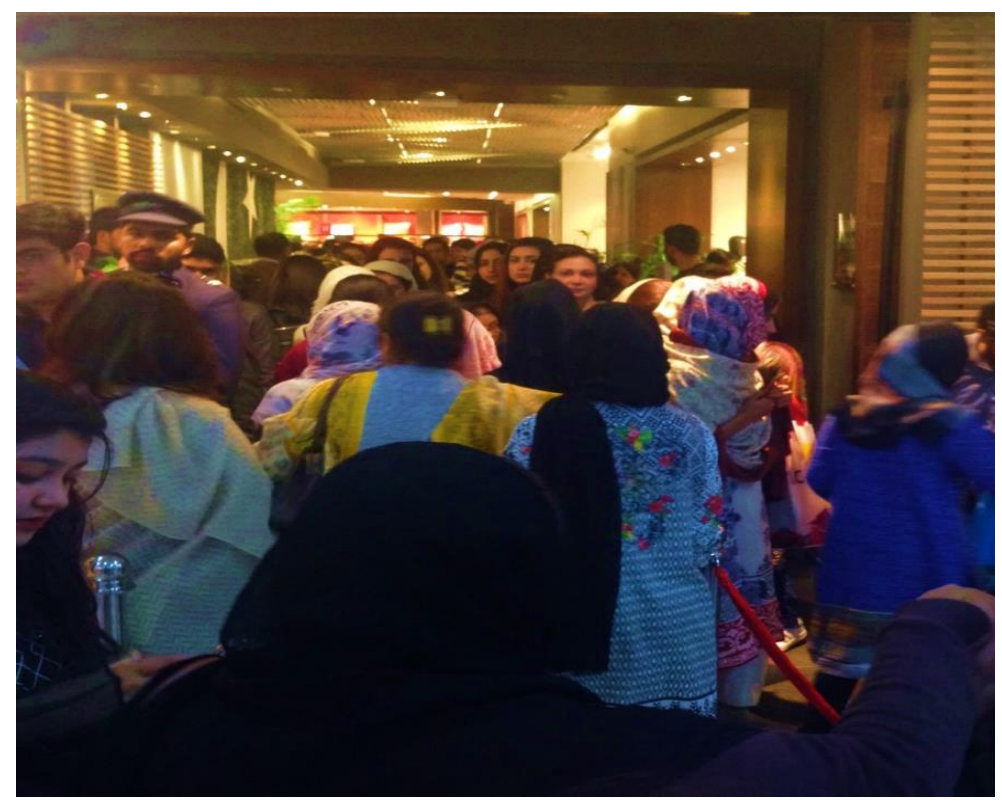

Fig. 1: Consumers crowd in front of a shop 
Observation note: Due to too much crowd one of the consumers got charged double for a single set of a bed sheet that she bought. She went back to return it but the retailers did not change it because of so much hustle. So, the lady left without doing anything as she was too tired because of the crowd and hustle. Her daughter asked her to go back and get it replaced but she was not in the mood to go back and argue with them.

This shows the side effects of Black Friday which include huge consumers doing crazy things to get the desired products. This example shows the mismanagement of the retailer to handle the thing adequately. Thus, Pakistani retailers need to pay attention to such things more in the future so that the consumers can be facilitated in a better way. According to Rose and Neidermeyer (1999), the physical environment plays a key role in influencing aggressive behavior with the help of emotions such as odor, temperature, and crowding.

\section{STORE TEMPERATURE}

The factor of store temperature was concluded as an anticipated factor because it made the consumers annoyed.

Observation note: The consumers were exhausting standing in the queues and it felt like a hot summer day instead of the cold November.

So, the first factor is the temperature of the store that caused irritation among the consumers who were wearing warm clothes but the stores were even warmer. In figure 6, one of the consumers can be seen as having his jacket on his arms instead of wearing it showing the hot temperature of the shop due to the excessive crowd.

\section{LONG QUEUES}

Observation note: The stores had long queues of people waiting to pay the bill and during the whole process they were bumping into each other.

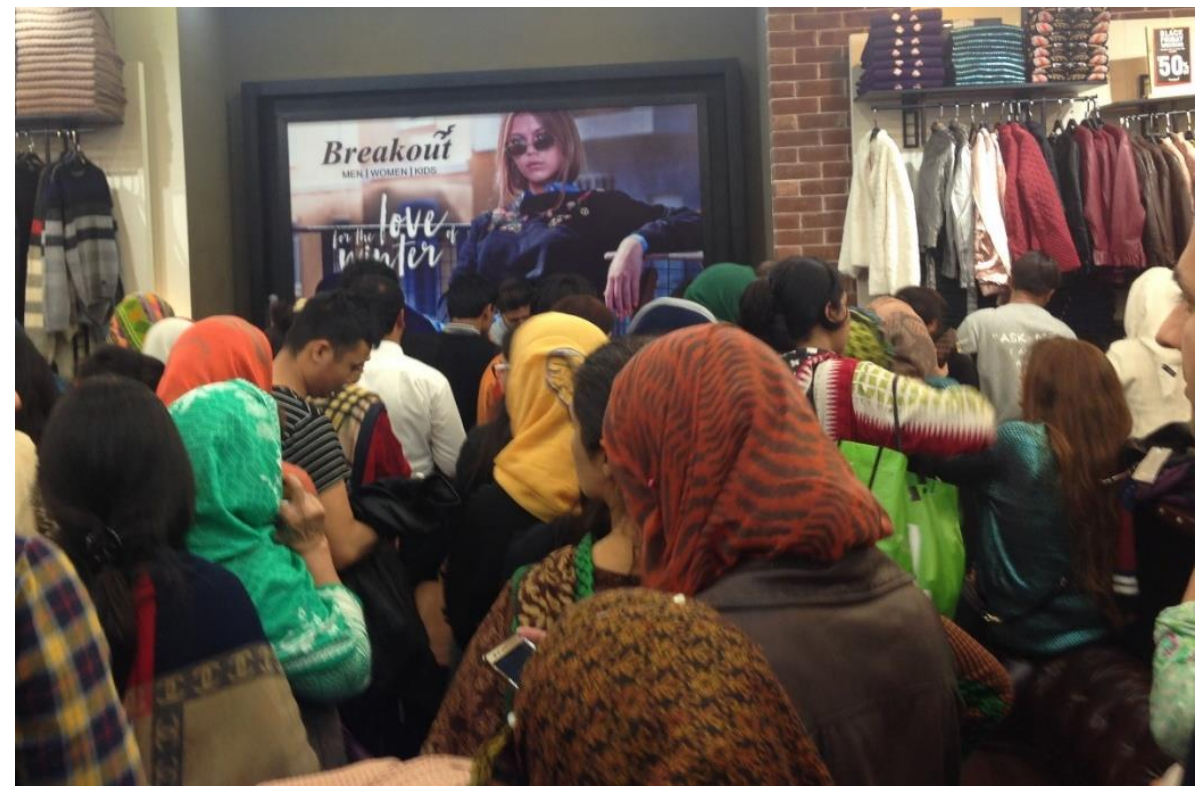

Fig. 2: Consumers standing in the long queue and have the jacket in their hands 
So, the next factor is of standing in the long queues that is why the consumers were bumping into each other. This bumping can eventually lead to the misbehavior of consumers.

\section{Closing STORE DURING BREAK}

Observation note: Some of the consumers were found fighting with the employees when they tried to close the store for Namaz (prayer) break. The consumers were not letting them have a prayer break.

As mentioned before Pakistan is an Islamic country and Friday is considered a blessed day. There is a special prayer (Jummah prayer) that people have to offer after $12 \mathrm{pm}$. The consumers were seen fighting with the employees on this issue of closing the store for a prayer break. This closing of the store made the consumer to misbehave.

\section{BROKEN POINT OF SALE TERMINAL}

Observation note: The payment terminals in most of the shops were down due to the overload. Because of which one couple fought with the employee of the shop. The consumers who were in the queues were also having issues due to the mismanagement of the retailers and the whole payment terminal issues as not everyone had cash with them. Most of them were carrying a debit or credit card. The same couple fought with another consumer too over this issue as they thought he took too much time in transacting the bill and they thought they were waiting for more time than him.

The consumers misbehaved because of the frustration of not being able to pay through the mode they had for payment. It was long queues to pay the bill so they started to get frustrated during the whole process then the payment terminal being down was the last nail in the coffin kind of thing.

The following conceptual framework of the factors that stimulated and have the ability to generate the consumer misbehavior was established. The conceptual framework was proposed based on the themes discussed above.

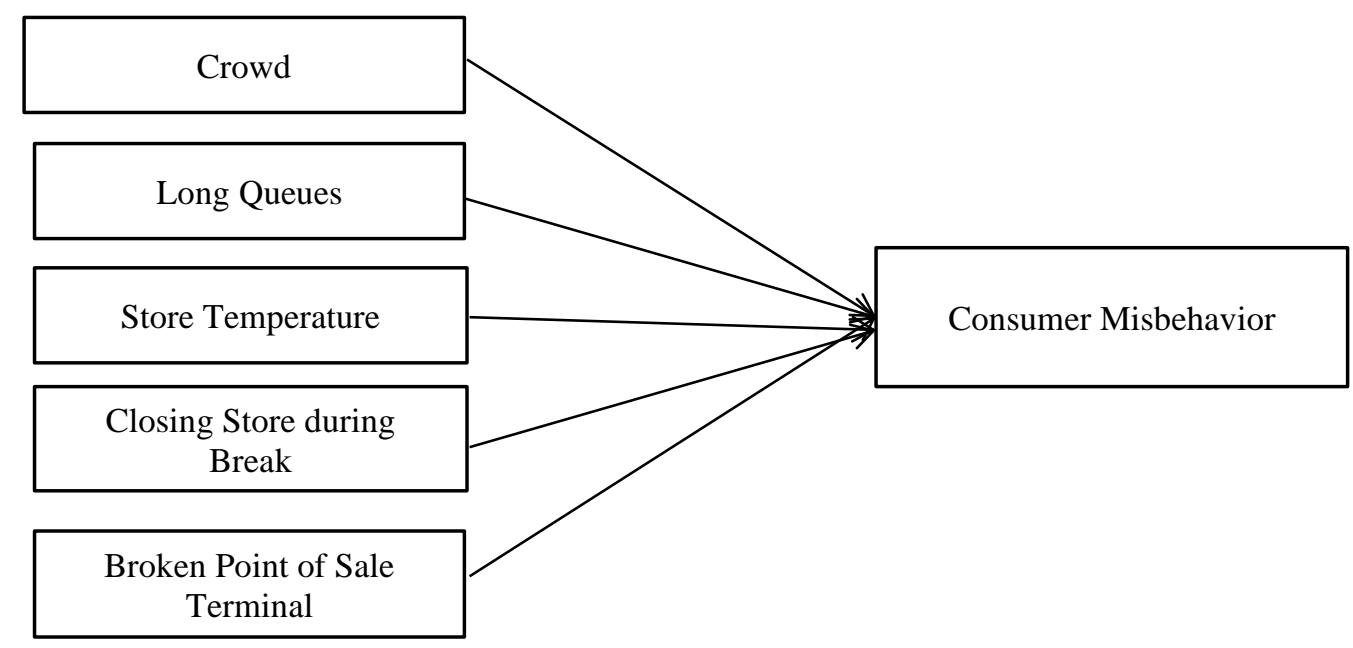

Fig. 3: Proposed Conceptual Framework of Factors Impacting Consumer Misbehavior 


\section{CONCLUSION}

The current research was conducted during the Black Friday sale event to explore the predictors of consumer misbehavior in clothing retail shops. An observational study approach was used to observe the factors presented in the environment that lead to the consumer to misbehave and could lead in the future too. Because of the occurrence of two such specific events (closing store during break and broken point of sale terminal) witnessed by the researcher that lead consumers to misbehave, five themes were generated. The objective of this study was to explore the behaviors of Pakistani consumers related to the Black Friday sale. After doing observations of the consumers during the sale day five major factors were generated in general. Some of the factors were found to have caused consumers to misbehave in the environment whereas some were presented based on literature.

\section{RESEARCH IMPLICATIONS}

This research explored the misbehaving stimulators of Pakistani consumers on the day of the Black Friday sale that is an addition to the existing literature as the Pakistani consumer's perspective was missing. The literature on consumer misbehavior lacks the impacting factors of consumer misbehavior during the Black Friday sale day. This research fills that gap by proposing a conceptual framework.

As for the retailers, they can solve this problem of misbehavior by being more active and check their machines before such a big sale event. They need to take the necessary precautions before arranging such a big sale. The crowd needs to be maintained with a proper pre-sale plan. The store temperature has to be according to the need of the consumers instead of being in accordance with the general weather. For example, the retailers (of the understudy mall) should have turned on the air conditioners despite it being the winters. There are higher chances that that would have calmed the consumers. For the long queues' problem, the retailer can distribute some discount vouchers to make the wait worth the consumers' time. The retailers can announce the timings of prayer or lunch break one hour prior to the break. This can give time to the consumers to be mentally prepared for the coming break. The retailers can solve this problem by doing this and prevent the consumer experience from decreasing.

\section{FUTURE RECOMMENDATIONS}

This research was conducted on a single day and the factors were generated based on observation so, in the future, research can be conducted by doing focus group or indepth interviews. The researchers took only one mall for the observation which is a limitation of the research. Further researches can be done by dividing the day into two malls or so. Quantitative research can be done by using this research's proposed conceptual model. How males and females misbehave differently can be researched by using the proposed model (Gilal, Zhang, Gilal, \& Gilal, 2020). 


\section{Reference:}

Akbari, M., Abdolvand, M. A. \& Ghaffari, F., 2016. Developing a model in antecedents of consumer misbehavior on chain stores. Brazilian Journal of Marketing - BJM, 15(2), pp. 146-164.

Amelia, A. \& Ronald, R., 2017. Can Customer Misbehavior Be Controlled? Case study on retail industry consumer behavior in Indonesia. Review of Integrative Business and Economics Research, 6(1), pp. 249-263.

Amine, A. \& Gicquel, Y., 2011. Rethinking resistance and anti-consumption behaviours in the light of the concept of deviance. European Journal of Marketing, 45(11-12), pp. 1809-1819.

Blau, R., 2015. Black Friday brings pain for family of Walmart worker killed. [Online] Available at: http://www.nydailynews.com/new-york/black-friday-brings-pain-family-walmartworker-killed-article-1.2447949 [Accessed 41 2016].

Burke, M. \& Agencies, a., 2014. Black Friday: Carnage in UK Tesco supermarkets as shoppers fight to get bargains. [Online] Available at: http://www.telegraph.co.uk/finance/businessclub/business-club-video/consumer-andretail-sector-vide/11259723/Black-Friday-Carnage-in-UK-Tesco-supermarkets-asshoppers-fight-t [Accessed 31 2016].

Cova, B., Gaglio, G., Weber, J. \& Chanial, P., 2018. Organizational sensemaking of non ethical consumer behavior: Case study of a French mutual insurance company.. Journal of Business Ethics, 148(4), pp. 783-799.

Creswell, J. W., 2007. Qualitative inquiry \& research design: Choosing among five approaches. 2nd ed. Los Angeles: SAGE Publications, Inc..

Daunt, K. L., \& Greer, D. A. (2015). Unpacking the perceived opportunity to misbehave: The influence of spatio-temporal and social dimensions on consumer misbehavior. European Journal of Marketing, 49(9-10), 1505-1526.

Dootson, P., Johnston, K. A., Beatson, A. \& Lings, I., 2016. Where do consumers draw the line? Factors informing perceptions and justifications of deviant consumer behaviour. Journal of Marketing Management, 32 (7-8), pp. 750-776.

Dubuis, A. \& Bucktin, C., 2015. Black Friday 2015: Brutal fights break out in American malls as shoppers clash over best deals. [Online] Available at: http://www.mirror.co.uk/news/worldnews/black-friday-2015-brutal-fights-6909924 [Accessed 22 2016].

Egan, V. \& Taylor, D., 2010. Shoplifting, unethical consumer behaviour, and personality. Personality and Individual Differences, 48(8), pp. 878-883.

Everton, W. J., Jolton, J. A. \& Mastrangelo, P. M., 2007. Be nice and fair or else: Understanding reasons for employees' deviant behaviors. Journal of Management Development, 26 (2), pp. 117-131.

Fullerton, R. A. \& Punj, G., 1993. Choosing to misbehave: A structural model of aberrant consumer behavior. Advances in Consumer Research, 20, pp. 570-574.

Fullerton, R. A., \& Punj, G. (1997). What is consumer misbehavior? Advances in Consumer Research, 24, 336-339.

Fullerton, R. \& Punj, G., 2004. Repercussions of promoting an ideology of consumption: Consumer misbehavior. Journal of Business Research, 57(11), p. 1239- 1249.

Ghazi, S. H., 2015. Women, power, privilege and Black Friday videos in Pakistan. [Online] Available at: http://blogs.tribune.com.pk/story/30579/women-power-privilege-and-black-fridayvideos-in-pakistan/[Accessed 0701 2018].

Gilal, F. G., Zhang, J., Gilal, R. G. \& Gilal, N. G., 2020. Linking motivational regulation to brand passion in a moderated model of customer gender and age: An organismic integration theory perspective. Review of Managerial Science, 14(1), pp. 87-113.

Glanfield, E., Cockroft, S. \& Smith, J., 2014. Stampede of the sales 'animals': Black Friday frenzy turns violent as shoppers fight over bargains. [Online] Available at: 
http://www.dailymail.co.uk/news/article-2852585/Mayhem-Black-Friday-beginsShoppers-clash-supermarkets-trying-grab-bargains-Boots-Game-Curry-s-PC-world-web [Accessed 72 2016].

GraanaBlog, 2019. Best shopping malls in Islamabad. [Online] Available at: https://blog.graana.com/shopping-malls-in-islamabad/ [Accessed 20 September 2020].

Grenoble, R., 2015. These people got way too aggressive on black Friday videos of the brawl that broke out in local stores this year. [Online] Available at: http://www.huffingtonpost.com/entry/black-friday-fights-deals2015 us 56587710e4b072e9d1c1e73f [Accessed 102 2016].

Harris, L. C. \& Daunt, K., 2013. Managing customer misbehavior: Challenges and strategies. Journal of Services Marketing, 27(4), p. 281-293.

Harris, L. C. \& Daunt, K. L., 2011. Deviant customer behaviour: A study of techniques of neutralisation. Journal of Marketing Management, 27(7-8), pp. 834-853.

Harris, L. C., \& Dumas, A. (2009). Online consumer misbehaviour: An application of neutralization theory. Marketing Theory, 9(4), 379-402.

Harris, L. C. \& Reynolds, K. L., 2004. Jaycustomer behavior: An exploration of types and motives in the hospitality industry. Journal of Services Marketing, 18 (5), pp. 339-357.

Hofstede, G., 2011. Dimensionalizing cultures: The Hofstede model in context. Online Readings in Psychology and Culture, 2(1), pp. 1-26.

Hofstede-Insights, 2020. Country Comparison. [Online] Available at: https://www.hofstedeinsights.com/country-comparison/pakistan, the-uk,the-usa/

Hoftstede, 1991. Cultures and organizations, software of the mind. New York: McGraw-Hill.

Kim, H. \& Qu, H., 2018. The effects of experienced customer incivility on employees' behavior toward customers and coworkers. Journal of Hospitality \& Tourism Research, 43(1) pp. 1-20.

Lennon, S. J., Johnson, K. K. P. \& Lee, J., 2011. A perfect storm for consumer misbehavior: Shopping on black Friday. Clothing \& Textiles Research Journal , 29 (2 ), pp. 119-134.

Lennon, S. J., Kim, M., Lee, J. \& Johnson, K. K. P., 2017. Effects of emotions, sex, self-control, and public self-consciousness on Black Friday misbehavior. Journal of Global Fashion Marketing, 8(3), pp. 1-17.

Lennon, S. J., Lee, J., Kim, M. \& Johnson, K. K. P., 2014. Antecedents of consumer misbehaviour on black Friday: A social responsibility view. Fashion, Style \& Popular Culture, 1(2), pp. 193-212.

Mangi, F., 2017. 135 Million Millennials Drive World's Fastest Retail Market. [Online] Available at: https://www.bloomberg.com/news/articles/2017-09-28/135-million-millennials-driveworld-s-fastest-retail-market [Accessed 0701 2018].

Moore, E. \& Llompart, J., 2017. Collecting, transcribing, analyzing and presenting plurilingual interactional data. Research-publishing. net., pp. 403-417.

Moschis, G. P. \& Cox, D., 1989. Deviant consumer behavior. Advances in Consumer Research, 16 , pp. 732-737.

Pruitt, S., 2015. What's the retail history of Black Friday? [Online] Available at: http://www.history.com/news/whats-the-real-history-of-black-Friday_[Accessed 102 2016].

Raymen, T. \& Smith, O., 2015. What's deviance got to do with it? Black Friday sales, violence and hyperconformity. British Journal of Criminology, 56(2), pp. 1-17.

Reynolds, K. L. \& Harris, L. C., 2006. Deviant customer behavior: An exploration of frontline employee tactics. Journal of Marketing Theory and Practice, 14(2), pp. 95-111.

Reynolds, K. L. \& Harris, L. C., 2009. Dysfunctional customer behavior severity: An empirical examination. Journal of Retailing, 85 (3), p. 321-335. 
Rose, R. L. \& Neidermeyer, M., 1999. From rudeness to road rage: The antecedents and consequences of consumer aggression. Advances in Consumer Research, Volume 26, pp. 12-17.

Simpson, L., Taylor, L., O'Rourke, K. \& Shaw, K., 2011. An analysis of consumer behavior on black Friday. American International Journal of Contemporary Research, 1(1), pp. 1-5.

Terblanche, N. S., 2018. Revisiting the supermarket in-store customer shopping experience. Journal of Retailing and Consumer Services, 40, p. 48-59.

Tribune, 2019. Watch women thrashes sales girl at Lahore mall over 'not having a mirror'. [Online] Available at: https://tribune.com.pk/story/2033401/1-watch-woman-thrashes-salesgirllahore-mall-not-mirror

Tribune, T. E., 2015. Black Friday: "We made history" says Muneeb Maayr, CEO Daraz.pk. [Online] Available at: https://tribune.com.pk/story/1003815/black-fridaywe-made-history-saysmuneeb-maayr-ceo-daraz-pk/[Accessed 0801 2018].

Tribune, T. E., 2016. Daraz Black Friday 2016 - Pakistan's first one billion rupee sale. [Online] Available at: https://tribune.com.pk/story/1247813/daraz-black-friday-2016-pakistans-first-onebillion-rupee-sale/[Accessed 0801 2018].

Wang, S.-P., Chen, M.-S. \& Li, M.-J., 2018. Key factors affecting deviant workplace behavior. African Journal of Business Management, 12(10), pp. 258-266.

Wheatstone, R., Ferguson, K. \& Clarke, J., 2015. Boxing day sale: fights between bargain-hunters and queues stretching up to 4,000 people in 3.74billion bonanza. [Online] Available at: http://www.mirror.co.uk/news/uk-news/boxing-day-sales-fights-between-7071631 [Accessed 102 2016].

Yagil, D., 2017. There is no dark side of customer aggression It's all dark. Journal of Marketing Management, 33(15-16), pp. 1413-1420. 